\title{
Bacterial Dispersal Promotes Biodegradation in Heterogeneous Systems Exposed to Osmotic Stress
}

\begin{abstract}
Anja Worrich 1,2, Sara König 1,3, Thomas Banitz ${ }^{3}$, Florian Centler ${ }^{1}$, Karin Frank ${ }^{3,4,5}$, Martin Thullner ${ }^{1}$, Hauke Harms ${ }^{1,4}$, Anja Miltner ${ }^{2}$, Lukas Y. Wick ${ }^{1 *}$ and Matthias Kästner ${ }^{2}$

${ }^{1}$ UFZ - Helmholtz Centre for Environmental Research, Department of Environmental Microbiology, Leipzig, Germany, ${ }^{2}$ UFZ - Helmholtz Centre for Environmental Research, Department of Environmental Biotechnology, Leipzig, Germany, ${ }^{3}$ UFZ - Helmholtz Centre for Environmental Research, Department of Ecological Modelling, Leipzig, Germany, ${ }^{4}$ German Centre for Integrative Biodiversity Research (iDiv) Halle-Jena-Leipzig, Leipzig, Germany, ${ }^{5}$ Institute for Environmental Systems Research, University of Osnabrück, Osnabrück, Germany
\end{abstract}

Contaminant biodegradation in soils is hampered by the heterogeneous distribution of degrading communities colonizing isolated microenvironments as a result of the soil architecture. Over the last years, soil salinization was recognized as an additional problem especially in arid and semiarid ecosystems as it drastically reduces the activity and motility of bacteria. Here, we studied the importance of different spatial processes for benzoate biodegradation at an environmentally relevant range of osmotic potentials $\left(\Delta \Psi_{0}\right)$ using model ecosystems exhibiting a heterogeneous distribution of the soil-borne bacterium Pseudomonas putida KT2440. Three systematically manipulated scenarios allowed us to cover the effects of (i) substrate diffusion, (ii) substrate diffusion and autonomous bacterial dispersal, and (iii) substrate diffusion and autonomous as well as mediated bacterial dispersal along glass fiber networks mimicking fungal hyphae. To quantify the relative importance of the different spatial processes, we compared these heterogeneous scenarios to a reference value obtained for each $\Delta \Psi_{\circ}$ by means of a quasi-optimal scenario in which degraders were ab initio homogeneously distributed. Substrate diffusion as the sole spatial process was insufficient to counteract the disadvantage due to spatial degrader heterogeneity at $\Delta \Psi_{\mathrm{o}}$ ranging from 0 to $-1 \mathrm{MPa}$. In this scenario, only $13.8-21.3 \%$ of the quasi-optimal biodegradation performance could be achieved. In the same range of $\Delta \Psi_{\circ}$ values, substrate diffusion in combination with bacterial dispersal allowed between 68.6 and $36.2 \%$ of the performance showing a clear downwards trend with decreasing $\Delta \Psi_{0}$. At $-1.5 \mathrm{MPa}$, however, this scenario performed worse than the diffusion scenario, possibly as a result of energetic disadvantages associated with flagellum synthesis and emerging requirements to exceed a critical population density to resist osmotic stress. Network-mediated bacterial dispersal kept biodegradation almost consistently high with an average of $70.7 \pm 7.8 \%$, regardless of the strength of the osmotic stress. We propose that especially fungal network-mediated bacterial dispersal is a key process to achieve high functionality of heterogeneous microbial ecosystems also at reduced osmotic potentials. Thus, mechanical stress by, for example, soil homogenization should be kept low in order to preserve fungal network integrity.

Keywords: spatial processes, heterogeneity, biodegradation, dispersal networks, Pseudomonas putida, osmotic stress, diffusion, contaminants 


\section{INTRODUCTION}

Bacterial degradation of contaminants prevents their persistence in the environment as well as the contamination of water resources due to leaching (Arias-Estévez et al., 2008). However, the distribution of bacterial degraders in soils shows a distinct spatial heterogeneity in both horizontal (Vinther et al., 2008) and vertical (Badawi et al., 2013) direction. For nearly a century, spatial heterogeneity was considered only a largescale phenomenon (Dechesne et al., 2014), and microbial ecologists stuck to the "Everything is everywhere" paradigm suggesting that microorganisms are mostly cosmopolitan and almost homogeneously distributed (Cho and Tiedje, 2000). Owing to intensive work on spatial heterogeneity in soil, the endemism hypothesis for bacteria is now generally accepted (Cho and Tiedje, 2000; Fulthorpe et al., 2008) and there is increasing awareness that heterogeneity is not only a fieldscale phenomenon, but similarly occurs at the micro-scale (Vieublé Gonod et al., 2006). Studies on the distribution of 2,4-dichlorophenoxyacetic acid (2,4-D) degraders in soil and soil column systems confirmed the existence of soil regions comprising several millimeters right up to a few centimeters, which are devoid of 2,4-D degrading activity (Pallud et al., 2004; Vieublé Gonod et al., 2006; Pinheiro et al., 2015). However, the majority of publications dealing with spatial heterogeneity of bacterial degraders in soils are rather descriptive, whereas the consequences of these small-scale spatial heterogeneities on biodegradation efficiency are difficult to assess and thus have hardly been evaluated so far (Dechesne et al., 2014).

Bacterial dispersal and substrate mass transfer are considered key factors for efficient biodegradation as both processes help to overcome spatial separation, thus leading to increased contact probability between bacteria and contaminants in a spatially heterogeneous environment like soil (Semple et al., 2007). Motility is a highly conserved trait among bacteria and more than two thirds of the sequenced species are motile, indicating that it provides bacteria with an essential ecological advantage (Czaban et al., 2007; Wei et al., 2011). Motile bacteria, for example, can actively disperse in the pore water and spread along dense mycelial networks formed by fungi leading to improved phenanthrene biodegradation (Wick et al., 2007).

Besides being often contaminated, soils are highly affected by salt accumulation due to low rainfall and high evapotranspiration (Rengasamy, 2006). Globally, more than 831 million hectares of land are affected by salt at levels causing osmotic stress in bacteria (Martinez-Beltran and Manzur, 2005). Recently, it was shown that the presence of mycelium-like networks improved dispersal, growth, and biodegradation under environmental stress conditions induced by lowered water potentials (Worrich et al., 2016). However, to what extent spatial processes like bacterial dispersal, network-mediated bacterial dispersal, or substrate diffusion may counteract the disadvantage due to a heterogeneous degrader distribution at different osmotic potentials remains unclear. Indeed, it is highly relevant to investigate whether and under which environmental conditions the spatial heterogeneity of degrading bacteria has to be taken into account in order to (i) improve models of microbial biodegradation in soils, (ii) predict contaminant fate in the environment, and (iii) derive strategies for risk assessment and management (Holden and Firestone, 1997; Soulas and Lagacherie, 2001).

Here, we aimed at quantifying the effect of different spatial processes (i.e., bacterial dispersal and substrate diffusion) on biodegradation efficiency at a range of environmentally relevant osmotic potentials, which are known to cause restrictions in bacterial growth and motility. We tested the hypothesis that to some extent autonomous bacterial dispersal but especially the dispersal along mycelia is crucial to counteract the disadvantages evoked by spatial degrader heterogeneity as sufficient compensation cannot be achieved by substrate diffusion alone. Furthermore, we wanted to assess whether there is a certain threshold at which not the spatial processes but rather the physiological limitations control biodegradation efficiency. In a microbial model system, we created different scenarios permitting solely substrate diffusion, or substrate diffusion and autonomous bacterial dispersal, or the two aforementioned processes plus network-mediated bacterial dispersal. A comparison of the respective scenarios to a reference scenario exhibiting a homogeneous degrader distribution allowed for a relative quantification of the biodegradation promoting effects for the different spatial processes.

\section{METHODS}

\section{Organisms and Culture Conditions}

Experiments were carried out with a benzoate-degrading, GFP-tagged derivative of the soil bacterium Pseudomonas putida KT2440. It was cultivated in FAB minimal medium (Hansen et al., 2007) supplemented with $50 \mathrm{mM}$ sodium benzoate (FAB-50, Sigma-Aldrich, Munich, Germany) at room temperature with $150 \mathrm{rpm}$ rotary culture flask movement. For strain maintenance, bacteria were transferred weekly to FAB-50 plates containing $1.5 \%(\mathrm{w} / \mathrm{v})$ agar and incubated at room temperature.

\section{Bacterial Population Growth Kinetics under Osmotic Stress}

For a detailed analysis of the effects of different sodium chloride concentrations on bacterial growth kinetics, we measured the increase in optical density at $600 \mathrm{~nm}$ in 96-well microtiter plates $\left(\mathrm{OD}_{600}\right)$ in a plate reader (SpectraMAX 250, Molecular Devices, California U.S.) set to $25^{\circ} \mathrm{C}$. The wells were filled with $200 \mu \mathrm{l}$ FAB-50 supplemented with either $3.2,6.4,12.8$, and $19.2 \mathrm{~g} \mathrm{l}^{-1}$ of sodium chloride, which corresponds to $\Delta \Psi_{\mathrm{o}}$ of $-0.25,-0.5$, -1 , or $-1.5 \mathrm{MPa}$ (Holden et al., 1997). FAB-50 medium without sodium chloride served as $\Delta \Psi_{\mathrm{o}}=0 \mathrm{MPa}$ control treatment. To minimize edge effects, outer wells were filled with potassium phosphate buffer (PB, $10 \mathrm{mM}, \mathrm{pH}$ 7.2) and not used for growth analysis (Johnsen et al., 2002). Cells from a liquid culture were harvested by centrifugation at $8000 \mathrm{~g}$ for $10 \mathrm{~min}$. The pellet was washed once with $\mathrm{PB}$ and adjusted to an optical density of 20 with FAB-50 medium. Each well was inoculated with $2 \mu \mathrm{l}$ using a multichannel pipette. Plates thus contained 12 replicates per osmotic stress treatment. Measurements were carried out 
every 30 min over a total of $86 \mathrm{~h}$. Maximum specific growth rates $\left(\mu_{\max }\right)$ were determined by exponentially fitting the sections of highest increase in the growth curves. Maximum biomass yields were calculated from the maximum $\mathrm{OD}_{600}$ values of each replicate using a calibration curve for the correlation between dry biomass and $\mathrm{OD}_{600}$. Samples exhibiting different $\mathrm{OD}_{600}$ values were filtered through weighed cellulose nitrate membrane filters with a pore size of $0.22 \mu \mathrm{m}$ (Sartorius, Goettingen, Germany). After drying at $60^{\circ} \mathrm{C}$ for $48 \mathrm{~h}$, filters were weighed again with the increase determining dry biomass. Lag times were derived from the $\mathrm{x}$-axis intercept of the straight line in the maximum slope of a non-parametric spline fit function of the "grofit"-package in $\mathrm{R}$ (Kahm et al., 2010; R Core Team, 2014).

\section{Microcosm Setup}

To investigate the role of the different spatial processes, four different scenarios were created. The wells of clear and sterile 24-well flat-bottom microtiter plates were filled with either $1 \mathrm{ml}$ of FAB-50 minimal medium agar of $1 \%(\mathrm{w} / \mathrm{v})$ to allow for diffusion but completely restrict bacterial dispersal $\left(D_{\text {dif }}\right)$ or $0.3 \%(\mathrm{w} / \mathrm{v})$ to allow for bacterial dispersal and substrate diffusion $\left(D_{\text {dis }}\right)$. To test the influence of mediated bacterial dispersal $\left(D_{n e t}\right)$, a glass fiber net with an area weight of 14 $\mathrm{g} \mathrm{m}^{-2}$ (Mühlmeier composite, Bärnau, Germany) was placed on top of $0.3 \%(\mathrm{w} / \mathrm{v})$ agar (Supplementary Figure 1). The glass fiber net was cut into circular pieces of $\varnothing 1.2 \mathrm{~cm}$ using a cork borer. Subsequently, the pieces were heat sterilized at $450^{\circ} \mathrm{C}$ for $4 \mathrm{~h}$ in a muffle furnace and placed in the microcosms before inoculation with bacteria. To create the reference scenario with a homogeneous cell distribution $\left(D_{\text {hom }}\right)$, wells were filled with liquid FAB-50 minimal medium. Osmotic stress was induced similarly to the growth kinetics experiment. Different amounts of sodium chloride were added to the FAB50 liquid medium or agar prior to autoclaving. Agar and liquid medium without additional sodium chloride served as $\Delta \Psi_{\mathrm{o}}=0 \mathrm{MPa}$ control treatments. Before use, all agar plates were dried in a laminar flow cabinet for $5 \mathrm{~min}$.

\section{Microcosm Inoculation}

Cells were harvested from liquid culture by centrifugation at $8000 \mathrm{~g}$ for $10 \mathrm{~min}$ after $16 \mathrm{~h}$ of cultivation. The pellet was washed once with $\mathrm{PB}$ and adjusted to an optical density of 50 . Microcosms were inoculated in the center of each well with $0.2 \mu \mathrm{l}$ bacterial suspension $\left[\sim 2.4 \cdot 10^{6}\right.$ colony forming units $\left.(\mathrm{CFU})\right]$ using a microliter syringe. The needle was pricked deep into the agar ( $\sim 0.8 \mathrm{~cm}$; cf. Figure 1$)$ but did not touch the bottom of the microcosms during inoculation. Abiotic control treatments were left uninoculated. To achieve a homogeneous distribution of bacterial cells in the $D_{\text {hom }}$ scenarios, plates were shaken for $1 \mathrm{~min}$ at $300 \mathrm{rpm}$ on a rotary shaker. Plates were incubated under static conditions in plastic containers at room temperature in the dark.

\section{Bacterial Population Growth and Degradation Measurement}

Cell numbers and benzoate concentrations were determined after $6,24,30$, and $48 \mathrm{~h}$ in replicate multiwell plates. Well contents were carefully mixed with $2 \mathrm{ml} \mathrm{PB}$. For the agar experiments, the PB-agar slurry was subsequently transferred to a sterile Falcon tube and detachment of bacterial cells was carried out by vortexing and ultrasonication in a water bath with a frequency of $35 \mathrm{kHz}$ (Sonorex Super RK 255H, Bandelin, Berlin) for $1 \mathrm{~min}$. Culturable cells were analyzed as CFU. To this end, bacteria were spread on FAB-50 plates using the drop plate method as described earlier (Chen et al., 2003). Briefly, 10-fold dilution series of the supernatant were prepared directly in 96-well microtiter plates and $5 \mu \mathrm{l}$ of consecutive dilutions were dropped on the agar plate. Plates were incubated at $25^{\circ} \mathrm{C}$ for $48 \mathrm{~h}$. Droplets giving rise to

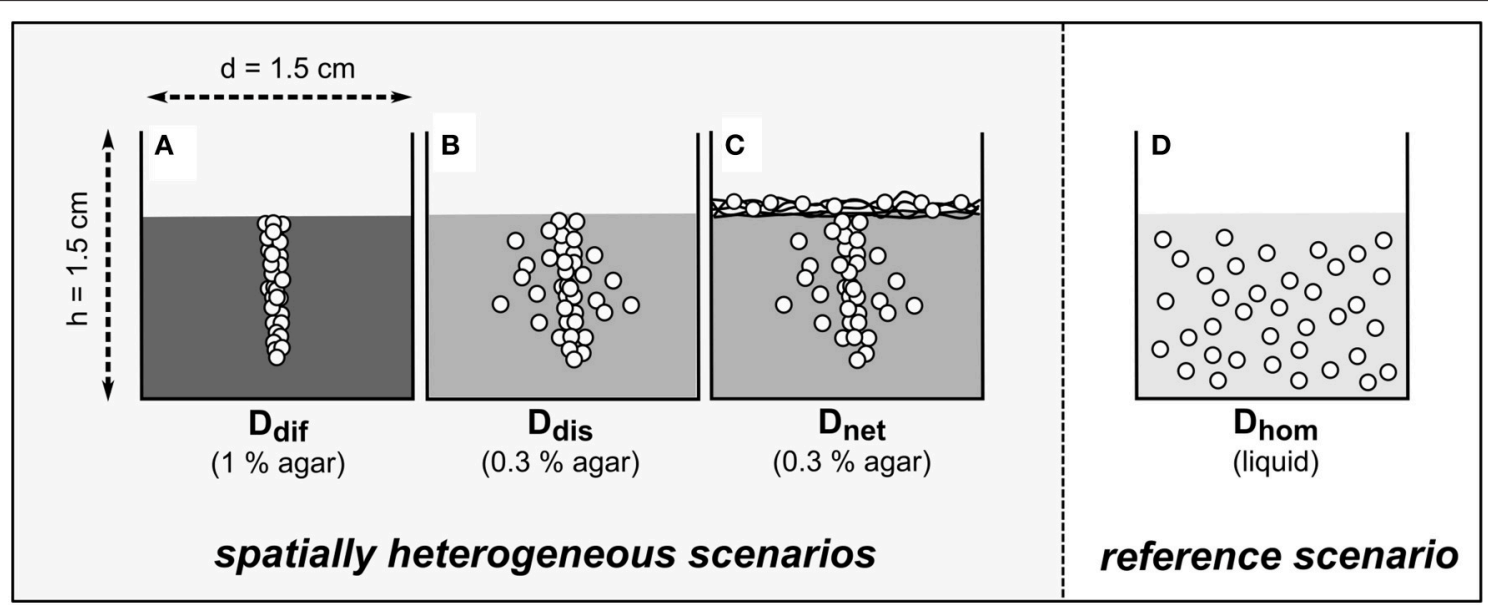

FIGURE 1 | Scheme of the model ecosystems used to assess the counteracting effects of substrate diffusion (A), substrate diffusion and autonomous bacterial dispersal (B), and substrate diffusion, autonomous bacterial dispersal, and network-mediated bacterial dispersal (C) on population growth and biodegradation in systems exhibiting a heterogeneous degrader distribution in comparison to a homogeneous reference scenario (D). White circles indicate the anticipated distribution of bacteria in matrices with increasing physical hindrance (indicated by shades of gray). Black lines (C) depict the glass fiber network used to simulate mycelial networks. In each treatment the osmotic potential $\Delta \Psi_{\mathrm{O}}$ was varied between 0 and $-1.5 \mathrm{MPa}$ using sodium chloride. 
between 5 and 30 single colonies were used to determine CFU numbers.

For benzoate measurements, the supernatant obtained from cell detachment was fixed with $4 \%$ (w/v) formaldehyde and filtered through $0.22 \mu \mathrm{m}$ syringe filters (Carl Roth, Karlsruhe, Germany) to remove bacteria. The benzoate concentration was determined with an HPLC system equipped with a $\mathrm{C}_{18}$ reverse phase column $(250 \times 4 \mathrm{~mm})$ and a Photodiode Array Detector (PDA) set at $271 \mathrm{~nm}$. The system was operated at a flow rate of $1.2 \mathrm{ml} \mathrm{min}-1,10 \mu \mathrm{l}$ injection volume and a mobile phase consisting of $80 \%$ sodium acetate $(50 \mathrm{mM}, \mathrm{pH} 4.5)$ and $20 \%$ $\mathrm{MeOH}$ (Warikoo et al., 1996). Benzoate had a retention time of $13.8 \mathrm{~min}$ under these operation conditions.

\section{Determination of the Relative Counteracting Effects of Bacterial Dispersal and Substrate Diffusion at Different Osmotic Potentials}

The extent to which bacterial dispersal and substrate diffusion are able to counteract the disadvantage caused by a heterogeneous degrader distribution at different osmotic potentials and thus to maintain benzoate biodegradation was analyzed by comparing the performance of the respective scenarios $\left(D_{\text {dif }}, D_{\text {dis }}\right.$, and $D_{\text {net }}$ ) with the performance of the $D_{\text {hom }}$ setup exhibiting a quasi-optimal homogeneous distribution of the degraders. We calculated the areas under the curve (AUC) for the time courses of benzoate biodegradation for the different distribution scenarios at the different osmotic potentials. The AUC serves as an aggregated measure of the temporal biodegradation performance and was calculated using the trapezoidal method in $\mathrm{R}$. This numerical approximation of the time integral allows for non-equidistant time data and, thus, is not hampered by missing measurements for certain points in time. The relative counteracting effects in terms of biodegradation performance (RCE) for each scenario $D_{i}$ in dependence of the osmotic potential $\Delta \Psi_{\mathrm{o}}$ were calculated according to:

$$
\operatorname{RCE}_{D_{i}, \triangle \Psi_{\mathrm{o}}}=\frac{\mathrm{AUC}_{D_{i}}}{\mathrm{AUC}_{D_{\text {hom }}}} ;\left(D_{1}=D_{\text {dif }} ; D_{2}=D_{\text {dis }} ; D_{3}=D_{n e t}\right) .
$$

\section{RESULTS}

\section{Bacterial Population Growth Kinetics under Osmotic Stress}

The obtained bacterial growth curves (Supplementary Figure 2) show a distinct response to different levels of osmotic stress created by the addition of sodium chloride. With decreasing $\Delta \Psi_{\mathrm{o}}$, the maximum specific growth rates were found to gradually decrease from $0.26 \mathrm{~h}^{-1}$ at $\Delta \Psi_{\mathrm{o}}=0 \mathrm{MPa}$ to $0.14 \mathrm{~h}^{-1}$ at $\Delta \Psi_{\mathrm{o}}=-1 \mathrm{MPa}$ and then dropped to $0 \mathrm{~h}^{-1}$ at $\Delta \Psi_{\mathrm{o}}=-1.5 \mathrm{MPa}$ (Figure 2A). A similar behavior was observed for maximum biomass, which showed only minor changes between $\Delta \Psi_{\mathrm{o}}=0 \mathrm{MPa}$ and $\Delta \Psi_{\mathrm{o}}=-1 \mathrm{MPa}$ (reduction from 0.32 to $0.3 \mathrm{mg}$ ) but markedly decreased to $0.03 \mathrm{mg}$ at $\Delta \Psi_{\mathrm{o}}=-1.5 \mathrm{MPa}$, which corresponds to the inoculated biomass
(Figure 2B). Lag times exhibited a different pattern as a drastic prolongation to $59 \mathrm{~h}$ was observed already at $\Delta \Psi_{\mathrm{o}}=-1 \mathrm{MPa}$ compared to $7.3 \mathrm{~h}$ at $\Delta \Psi_{\mathrm{o}}=0 \mathrm{MPa}$. At $\Delta \Psi_{\mathrm{o}}=-1.5 \mathrm{MPa}$, lag times could not be determined as no growth was observed within the duration of the experiments (Figure 2C).

\section{Effects of the Spatial Degrader Distribution on Biodegradation and Population Growth}

The spatial distribution of the bacterial population had a drastic impact on benzoate biodegradation and bacterial population dynamics. In the $D_{\text {hom }}$ scenario, the total amount of benzoate in the system was already degraded after $24 \mathrm{~h}$, whereas in the $D_{\text {dif }}$ scenario, only $11.1 \%$ of the total benzoate was consumed at this time point (Figure 3A, dotted and dot-dashed line). At the end of the experiment (after $48 \mathrm{~h}$ ), 26.1\% of the benzoate was consumed on average in the $D_{\text {dif }}$ scenario (i.e., when bacteria were trapped at the inoculation point, Figure 3A, dot-dashed line). In the $D_{\text {dis }}$ scenario, 41.2 and $64.3 \%$ of the benzoate was consumed after 24 and $30 \mathrm{~h}$, whereas in the $D_{\text {net }}$ scenario, benzoate consumption accounted for 80.7 and $90.3 \%$ at the respective time points (Figure $\mathbf{3 A}$, solid and dashed line). In both scenarios, the total amount of benzoate was degraded after $48 \mathrm{~h}$.

CFU numbers in the $D_{\text {dif }}$ scenario were roughly 23-fold lower compared to the $D_{\text {hom }}$ scenario after $24 \mathrm{~h}$ of incubation $\left(1.05 \cdot 10^{8}\right.$ and $2.39 \cdot 10^{9} \mathrm{CFU} \mathrm{ml}^{-1}$, respectively, Figure $\left.3 \mathrm{~F}\right)$. With increasing incubation time, CFU numbers in the $D_{\text {dif }}$ scenario steadily increased to $3.8 \cdot 10^{8} \mathrm{CFU} \mathrm{ml} \mathrm{m}^{-1}$ after $48 \mathrm{~h}$, whereas in the $\mathrm{D}_{\text {hom }}$ scenario CFU numbers already showed a decline at $30 \mathrm{~h}$ (Figure 3F, dot-dashed and dotted line). At $48 \mathrm{~h}, D_{\text {hom }}$ and $D_{\text {dif }}$ scenarios exhibited the same CFU number. In the $D_{\text {dis }}$ and $D_{\text {net }}$ scenarios, CFU numbers continuously increased to 1.35 . $10^{9}$ and $1.97 \cdot 10^{9} \mathrm{CFU} \mathrm{ml} \mathrm{m}^{-1}$ at $48 \mathrm{~h}$, respectively. However, in the $D_{n e t}$ scenario, we consistently observed a higher CFU number at the different time points (Figure 3F, dashed and solid line).

\section{Impact of Different Spatial Degrader Distributions on the Response of Biodegradation and Population Growth to Varying Osmotic Potentials}

Apparently, in the $D_{\text {hom }}$ scenario, a reduction of $\Delta \Psi_{\mathrm{o}}$ down to $-0.5 \mathrm{MPa}$ had no effect on biodegradation efficiency. After $24 \mathrm{~h}$, the entire benzoate added to the microcosms was degraded also at $\Delta \Psi_{\mathrm{o}}=-0.25 \mathrm{MPa}$ and $\Delta \Psi_{\mathrm{o}}=-0.5 \mathrm{MPa}$ (Figures 3A-C, dotted line). However, lower $\Delta \Psi_{\mathrm{o}}$ of $-1 \mathrm{MPa}$ and $-1.5 \mathrm{MPa}$ led to decelerated benzoate biodegradation in the $D_{\text {hom }}$ scenario (Figures 3D,E, dotted lines). At $\Delta \Psi_{\mathrm{o}}=-1 \mathrm{MPa}$, the benzoate in the $D_{\text {hom }}$ scenarios was almost completely degraded after $30 \mathrm{~h}(97.4 \%)$, whereas at $\Delta \Psi_{\mathrm{o}}=-1.5 \mathrm{MPa}$ still $18.9 \%$ remained in the microcosms after $48 \mathrm{~h}$ (Figures 3D,E). In the $D_{\text {dif }}$ scenario, we observed only minor changes in biodegradation with decreasing osmotic potentials (Figures 3A-E, dot-dashed line). After $48 \mathrm{~h}$, between $26.1 \%$ at $\Delta \Psi_{\mathrm{o}}=0 \mathrm{MPa}$ and $13.6 \%$ at $\Delta \Psi_{\mathrm{o}}=-1.5 \mathrm{MPa}$ of the total benzoate was degraded. 


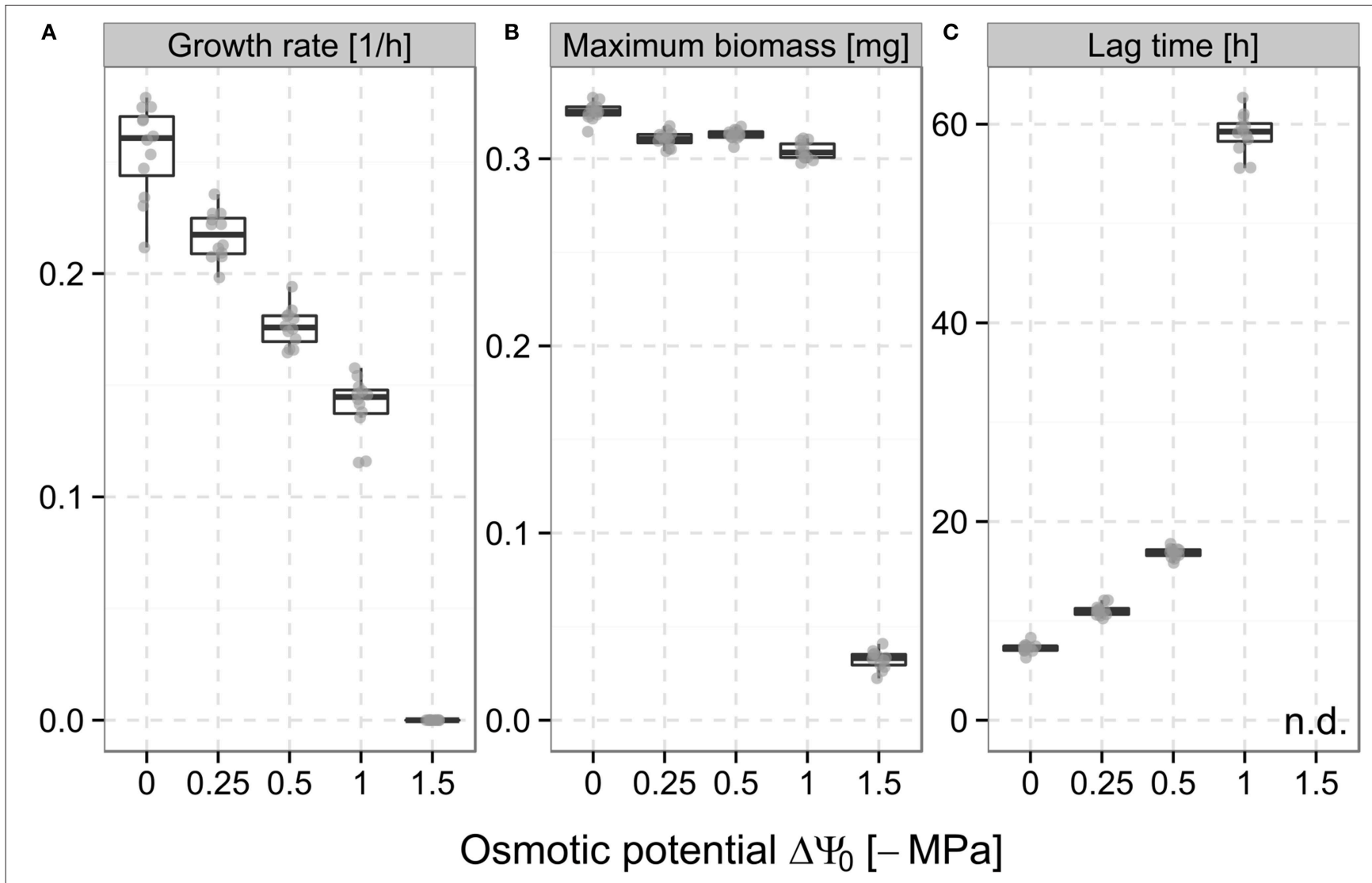

FIGURE 2 | Maximum specific growth rate (A), maximum biomass (B), and lag time (C) of Pseudomonas putida KT2440 during growth in liquid culture at the different osmotic potentials $\left(\Delta \Psi_{0}\right)$ adjusted with sodium chloride (cf. Section Bacterial Population Growth Kinetics under Osmotic Stress). Boxes show the medians and the interquartile range of values (between 25th and 75th percentile). Whiskers extend to values not more than 1.5-fold out of this range. Points represent the values of individual replicates (12 in total for each $\Delta \Psi_{\circ}$ ).

Biodegradation in the $D_{\text {dis }}$ scenario was markedly decelerated at lowered $\Delta \Psi_{\mathrm{o}}$. While at $\Delta \Psi_{\mathrm{o}}=-0.25 \mathrm{MPa}, 24.8 \%$ of the benzoate was consumed, we did not observe any biodegradation at $\Delta \Psi_{\mathrm{o}}=-1.5 \mathrm{MPa}$ after $24 \mathrm{~h}$. At the end of the experiments (after $48 \mathrm{~h}$ ), almost the whole amount of benzoate was degraded at $\Delta \Psi_{\mathrm{o}}$ ranging from 0 to $-1 \mathrm{MPa}$, whereas at $\Delta \Psi_{\mathrm{o}}=-1.5 \mathrm{MPa}$ still $97.2 \%$ of the benzoate was left in the microcosms. Also in the $D_{\text {net }}$ scenario, benzoate biodegradation was decelerated at lowered $\Delta \Psi_{0}$. However, the amount of degraded benzoate always exceeded the values obtained for the $D_{\text {dis }}$ scenario and still accounted for $57.2 \%$ at $\Delta \Psi_{\mathrm{o}}=-1.5 \mathrm{MPa}$.

Generally, bacterial population dynamics in the $D_{\text {hom }}$ scenario exposed to osmotic stress reflected the degradation patterns. Also here, drastic reductions in CFU numbers were observed at $\Delta \Psi_{\mathrm{o}}=-1 \mathrm{MPa}$ with a 6.7 -fold lower value compared to $\Delta \Psi_{\mathrm{o}}=0 \mathrm{MPa}$ after $24 \mathrm{~h}$ (Figures 3F,I, dotted lines). In the $D_{\text {dif }}$ scenario, CFU numbers remained very low for all osmotic potentials (Figures 3F-J, dash-dotted lines). Moreover, the final values (after $48 \mathrm{~h}$ ) also gradually decreased from $3.8 \cdot 10^{8}$ $\mathrm{CFU} \mathrm{ml}{ }^{-1}$ for $\Delta \Psi_{\mathrm{o}}=0 \mathrm{MPa}$ to $2.43 \cdot 10^{8}$ for $\Delta \Psi_{\mathrm{o}}=-1.5 \mathrm{MPa}$. For the $D_{\text {dis }}$ and $D_{\text {net }}$ scenarios, we observed decelerations similarly to the biodegradation patterns at decreasing $\Delta \Psi_{\mathrm{o}}$. Also final CFU numbers steadily decreased for both scenarios between $\Delta \Psi_{\mathrm{o}}$ of -0.25 and $-1.5 \mathrm{MPa}\left(1.35 \cdot 10^{9}\right.$ to $2.52 \cdot 10^{8} \mathrm{CFU} \mathrm{ml}^{-1}$ for $D_{\text {dis }}$ and $3 \cdot 10^{9}$ to $3.35 \cdot 10^{8} \mathrm{CFU} \mathrm{ml} \mathrm{m}^{-1}$ for $\left.D_{\text {net }}\right)$.

\section{Relative Counteracting Effects of Dispersal and Diffusion at Different Osmotic Potentials}

AUC values of $D_{\text {hom }}, D_{\text {dis }}$, and $D_{\text {net }}$ scenarios decreased with decreasing osmotic potentials, but remained almost stable at a low level in the $D_{\text {dif }}$ scenario (24.1 \pm 2.9 , Figure 4A; cf. Figures 3A-E). Relative counteracting effects (RCE) were calculated by dividing the AUC values for the $D_{d i f}, D_{d i s}$, and $D_{n e t}$ scenarios by the AUC value for the $D_{\text {hom }}$ scenario at each osmotic potential. In the $D_{\text {dif }}$ scenario, only $18.3 \%$ of the biodegradation performance relative to the $D_{\text {hom }}$ scenario was achieved at $\Delta \Psi_{\mathrm{o}}=0 \mathrm{MPa}$. At lowered $\Delta \Psi_{\mathrm{o}}$, RCE varied between $13.8 \%\left(\Delta \Psi_{\mathrm{o}}=-0.25 \mathrm{MPa}\right)$ and $21.3 \%\left(\Delta \Psi_{\mathrm{o}}=-1 \mathrm{MPa}\right)$, but increased to $48 \%$ at $\Delta \Psi_{\mathrm{o}}=-1.5 \mathrm{MPa}$ (Figure $4 \mathrm{~B}$, dot-dashed line). Autonomous bacterial dispersal $\left(D_{\text {dis }}\right)$ could maintain biodegradation to $68.6 \%$ at $\Delta \Psi_{\mathrm{o}}=0 \mathrm{MPa}$ and decreased only slightly at $\Delta \Psi_{\mathrm{o}}=-0.25 \mathrm{MPa}$. At $\Delta \Psi_{\mathrm{o}}=-0.5$ and $-1 \mathrm{MPa}$, 


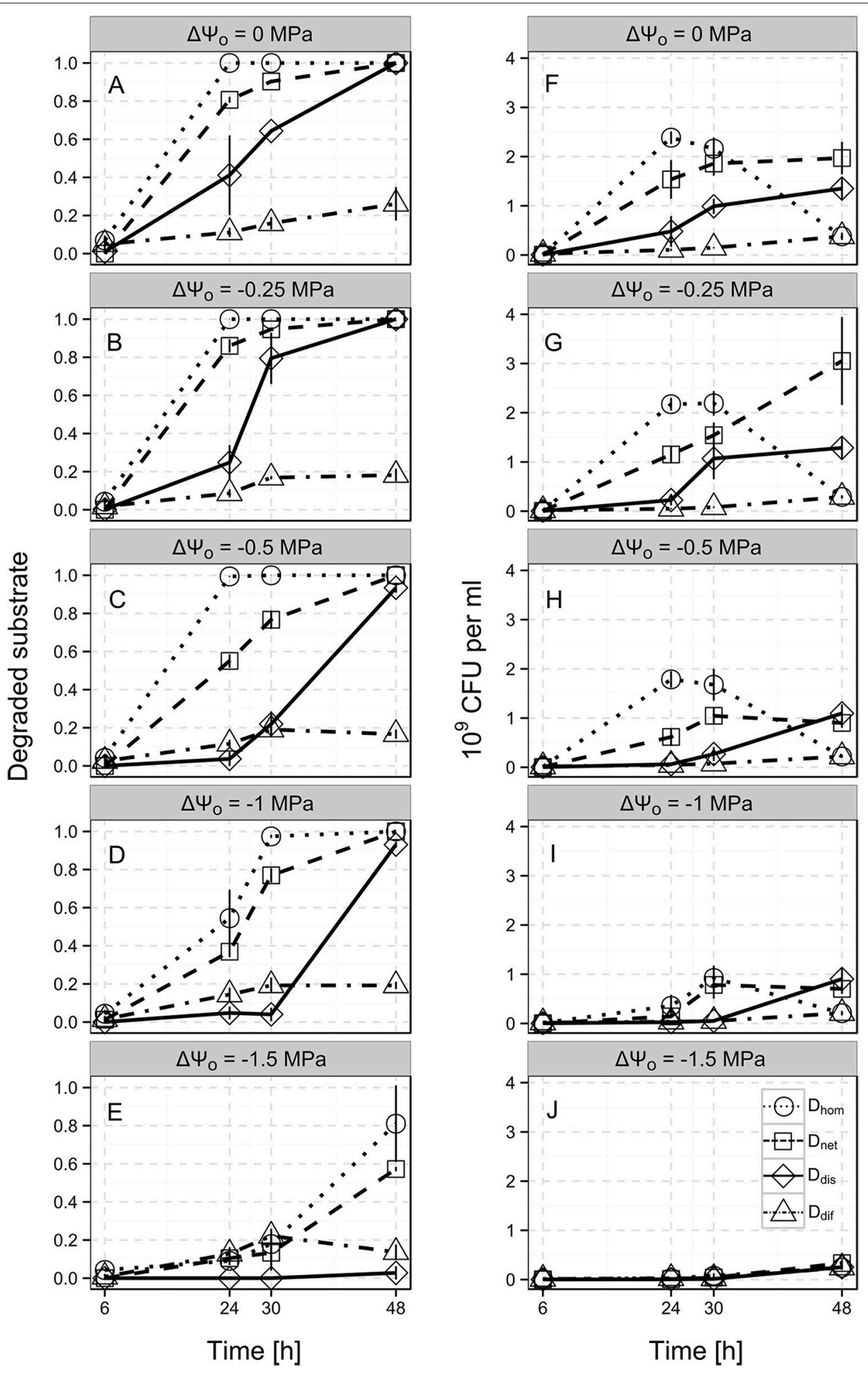

FIGURE 3 | Time-resolved benzoate biodegradation performance (A-E) and bacterial population size (F-J) of Pseudomonas putida KT2440 for the different scenarios $\mathrm{Di}$ at the different osmotic potentials $\left(\boldsymbol{\Delta} \boldsymbol{\Psi}_{\mathrm{O}}\right.$, indicated by the subplot labels). Single lines show three heterogeneous scenarios allowing for either solely substrate diffusion ( $D_{\text {dif }}$; dot-dashed lines), substrate diffusion and autonomous bacterial dispersal $\left(D_{\text {dis }}\right.$; solid lines), and substrate diffusion, autonomous bacterial dispersal and network-mediated bacterial dispersal ( $D_{\text {net }}$; dashed lines) and the reference scenario with a homogeneous cell distribution $\left(D_{\text {hom }}\right.$; dotted line). Benzoate biodegradation performance and population dynamics were assessed by the relative amounts of benzoate degraded and the CFU numbers after $6,24,30$, and $48 \mathrm{~h}$. Error bars represent the standard deviation from 4 biological replicates. 

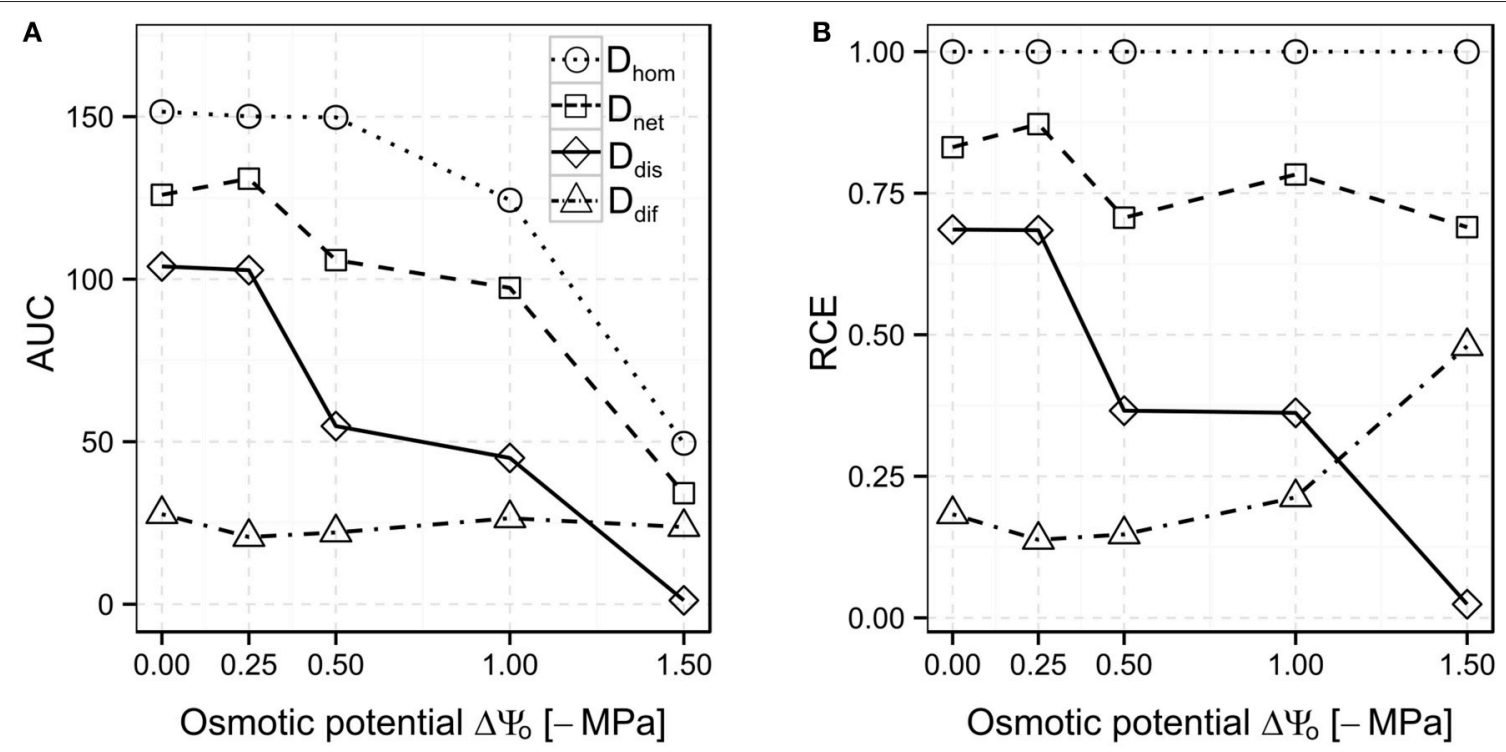

FIGURE 4 | Area under the curve (AUC; A) and Relative Counteracting Effects (RCE; B) calculated for the different scenarios $D i$ at different $\Delta \Psi_{0}$. For $R C E$ calculation, AUC values were divided by the AUC value of the reference scenario $D_{\text {hom }}$ (cf. Equation 1).

RCE dropped to 36.6 and $36.2 \%$, respectively (Figure 4B, solid line). However, we consistently obtained a higher RCE in the $D_{\text {dis }}$ compared to the $D_{\text {dif }}$ scenario at $\Delta \Psi_{\mathrm{o}}$ from 0 to $-1 \mathrm{MPa}$. The only exception occurred at $\Delta \Psi_{\mathrm{o}}=-1.5 \mathrm{MPa}$, where bacterial dispersal exhibited a lower RCE compared to $D_{\text {dis }}$ (RCE of 2.4 and $48 \%$, respectively, Figure $4 B$ ). In the $D_{\text {net }}$ scenario, RCE was always the highest compared to the other scenarios and varied between 87.2 and $69 \%$ over the range of osmotic potentials (Figure 4B, dashed line).

\section{DISCUSSION}

\section{Importance of the Spatial Degrader Distribution}

In this study, we tested how different spatial processes can counteract a heterogeneous degrader distribution. We compared biodegradation in scenarios allowing for different spatial processes to a scenario in which degraders were homogeneously distributed to mimic optimal distribution conditions. Salinity is known to affect bacterial dispersal and thus we analyzed how the counteracting effects change with decreasing osmotic potentials and if there is some kind of threshold at which not the spatial processes but rather the physiological limitations control biodegradation efficiency. The soil bacterium P. putida KT2440 was chosen because of its well-characterized motility behavior (Dechesne et al., 2010b), which recently was investigated also under osmotic stress conditions (Worrich et al., 2016). In our study, sodium benzoate served as a representative of polar, aromatic contaminants (e.g., pesticides) as its physicochemical properties are similar to those of 2,4-D, dicamba or fluroxypyr (Dechesne et al., 2010a).

A heterogeneous distribution of the cells concentrated at the inoculation point clearly limited bacterial population growth and biodegradation efficiency compared to the situation with a homogeneous distribution of bacterial cells in liquid cultures. This is in line with studies on 2,4-D biodegradation in soil columns showing that biodegradation is most efficient if degraders are uniformly dispersed (Pallud et al., 2004; Pinheiro et al., 2015). By systematically decreasing the heterogeneity of the spatial degrader distribution, Dechesne et al. (2010a) also found a clear improvement of benzoate mineralization. Here, we developed an approach to estimate the impact of spatial heterogeneity on biodegradation by assessing also the performance for a quasi-optimal distribution of degraders. Thus, we found in our experiments that biodegradation performance was at less than $19 \%$ of the quasi-optimal performance if diffusion was the sole spatial process that could potentially counteract the disadvantages caused by the spatial separation between bacteria and substrate. This observation emphasizes the big impact of small-scale spatial heterogeneities for contaminant biodegradation.

\section{Effects of the Spatial Degrader Distribution on the Response to Varying Osmotic Potentials}

We induced osmotic stress down to $\Delta \Psi_{\mathrm{o}}=-1.5 \mathrm{MPa}$ by adding different concentrations of sodium chloride to our experimental system, comparable to other studies (Holden et al., 1997; Chang et al., 2007). The lowest value was chosen because of its environmental relevance in representing permanent wilting point conditions for many agronomic plants in soil (Harris, 1981). In the homogeneous liquid culture system, biodegradation was reduced at $\Delta \Psi_{\mathrm{o}}=-1 \mathrm{MPa}$ probably as a result of the reduced population growth rates and extended lag times observed in the growth kinetic experiments 
(Figures 2A,B). Furthermore, a homogeneous cell distribution causes a high effective exposure of the bacteria to the osmotic stress across the microcosm area. In order to resist exposure to high concentrations of salts, bacteria have evolved stress tolerance mechanisms like the accumulation of osmolytes at concentrations that are proportional to the osmolarity of the medium (Csonka, 1989; Oren, 2001). However, synthesizing osmolytes requires large amounts of energy and thus poses a significant metabolic burden for microorganisms (Oren, 1999). As a consequence, less energy is available for growth explaining the delayed growth as well as the lowered final biomass yields observed with decreasing $\Delta \Psi_{\mathrm{o}}$.

In the scenario allowing only for substrate diffusion $\left(D_{\text {dif }}\right)$, the changing osmotic potentials had only a minor impact on population growth and biodegradation probably because the diffusion limitation is the major controlling factor masking the physiological limitations imposed by the osmotic stress. However, we assume that the restricted dispersal of the cells also leads to an accumulation in the inoculation point and thus shields the bacteria from the osmotic stress. This is in line with different biofilm studies reporting an increased resistance of aggregated bacteria compared to planktonic states also for osmotic stress (Wai et al., 1998).

Several studies have demonstrated that osmotic stress may affect soil microorganisms by reducing their biomass (Tripathi et al., 2006), amino acid uptake and protein synthesis (Norbeck and Blomberg, 1998), and respiration (Gennari et al., 2007). In addition, also serious consequences for the provision of ecosystem services were reported (Stark and Firestone, 1995). Following up on this, we could show that not only the spatial heterogeneity of the degraders but also their response to osmotic stress (i.e., to a decrease of $\Delta \Psi_{\mathrm{o}}$ ) has to be taken into account for the natural attenuation capacity of ecosystems.

\section{Effects of Bacterial Dispersal at Different Osmotic Potentials}

In the present study, bacterial movement through the agar matrix and along the dispersal networks was found to counteract the disadvantage due to spatial degrader heterogeneity at different osmotic potentials. The counteraction ability was higher in case of glass fiber networks, which had been shown to accelerate bacterial dispersal processes earlier (Banitz et al., 2011a; Worrich et al., 2016). Glass fibers were used to simulate hyphae surrounded by liquid films (Banitz et al., 2011b; Pion et al., 2013a) and to exclude effects of hyphal activities on bacterial growth and nutrition (Furuno et al., 2012; Banitz et al., 2013; Pion et al., 2013b; Schamfuß et al., 2013).

In this study we used the flagellated bacterium $P$. putida KT2440, which can disperse by swimming motility (Dechesne et al., 2010b). We used $0.3 \%$ agar in the experiments as this concentration is supposed to facilitate bacterial swimming through water filled channels in the agar matrix (Rashid and Kornberg, 2000). In addition, the movement of bacteria in the liquid films along fungal mycelia was shown to be enabled by flagella, as non-motile bacteria were not dispersed. It remains unclear whether this movement is associated to swimming or swarming motility (Kohlmeier et al., 2005). However, we never observed any cell movement on top of $0.5 \%$ agar plates probably because swarming in $P$. putida KT2440 relies on short pili, which are only expressed under specific conditions (Matilla et al., 2007). As the mechanisms underlying bacterial movement in our microcosms were not explicitly studied we referred to it more generally as dispersal.

Bacterial dispersal is considered a key factor for efficient biodegradation in soil (Harms and Wick, 2006; Banitz et al., $2011 \mathrm{~b}$ ) and the advantageous effects were reported several times (Wick et al., 2007; Dechesne et al., 2010a; Worrich et al., 2016). Here, we could show that bacterial dispersal is able to counteract the disadvantages caused by spatial degrader heterogeneity in our microcosm setup. However, at lowered $\Delta \Psi_{0}$, the benefit of bacterial dispersal in absence of dispersal networks vanished as a consequence of the osmotic stress which was shown to reduce dispersal of the bacterial population (cf. Supplementary Figure 3; Worrich et al., 2016). Bacterial dispersal is a result of growth, passive transport and motility. However, in previous experiments with a non-motile isogenic mutant of $P$. putida KT2440, we observed that growth and passive transport contributed only marginally to dispersal in the microcosms in absence of osmotic stress (Supplementary Videos 1, 2). Thus, it is likely that the reduced colony expansion observed in the experiments at lowered osmotic potentials is caused particularly by a restriction of bacterial motility. The high metabolic costs associated with the survival at low $\Delta \Psi_{\text {o }}$ probably led to a downregulation of motility genes to avoid further energetic disadvantages. Indeed, reduced expression of structural genes involved in flagellum synthesis has been observed for Pseudomonas, Bacillus, and Enterobacter strains under osmotic stress conditions (Soutourina et al., 2001; Kristoffersen et al., 2007). The minor effects shown for the scenario with the immobilized cells $\left(D_{d i f}\right)$ may thus further be associated with a higher energy status of the cells due to the repression of flagellum-synthesis under conditions leading to immobilization (high agar concentration in our experiments) similar to what was postulated for non-flagellated mutants of $P$. putida KT2440 showing a higher resistance to oxidative stress than the flagellated cells (Martinez-Garcia et al., 2014). At $\Delta \Psi_{\mathrm{o}}=-1.5 \mathrm{MPa}$, we observed bacterial dispersal exerting negative effects on benzoate biodegradation (Figure 3E). Recently, it was found that the colonization of stress-affected environments requires a critical population density in order to maintain activity in an antibiotic landscape (Hol et al., 2016). Possibly, this was the case also in our system for low $\Delta \Psi_{\mathrm{o}}$ and the primary colonizers leaving the inoculation site were not able to establish, thus reducing the overall activity in the system.

The network-mediated dispersal benefit also gradually decreased with decreasing $\Delta \Psi_{0}$. However, the presence of dispersal networks always led to improvements of bacterial population growth and biodegradation performance also at low $\Delta \Psi_{\mathrm{o}}$. We hypothesize that the presence of dispersal networks creates a trade-off with a more even bacterial coverage leading to increased substrate access, but simultaneously causing a higher effective exposure to the osmotic stress. Nevertheless, it seems that the network-mediated benefits for bacteria could 
compensate the energetic costs of dispersal and hence prevent the downregulation of motility genes. Probably, the potential accumulation of bacteria along the network may decrease the exposure to osmotic stress and helps to exceed the critical density threshold needed for establishment under lowered $\Delta \Psi_{\mathrm{o}}$.

\section{Importance of Spatial Processes at Different Osmotic Potentials}

Bacterial dispersal ability was identified to be crucial for the fast removal of the benzoate in our system. Although diffusion could partially secure biodegradation under the compounded effects of spatial degrader heterogeneity and varying $\Delta \Psi_{0}$, bacterial motility and especially the network-mediated dispersal led to considerably higher performances (Figure 4B). At low $\Delta \Psi_{0}$, not the spatial arrangement of the degrader population but rather the insufficient growth caused by the salt is the bottleneck for biodegradation as shown by the growth kinetics experiment as well as by the analysis of the homogeneous reference scenario $D_{\text {hom }}$ at the different $\Delta \Psi_{\mathrm{o}}$. Growth itself was considered as a non-spatial process as it was shown not to account for any significant changes in bacterial spatial dynamics (Pallud et al., 2004).

The influence of many soil physicochemical parameters has been measured in order to assess controlling factors determining biodegradation efficiency (Dechesne et al., 2014). However, only a few covariates have been found which represent good predictors for biodegradation activity including pH (Rodriguez-Cruz et al., 2006; Hussain et al., 2013) and moisture (Cruz et al., 2008; Monard et al., 2012). Soil $\mathrm{pH}$ was shown to particularly affect bacterial growth (Bååth and Arnebrant, 1994) whereas soil moisture was shown to particularly affect bacterial motility (Dechesne et al., 2010b). Therefore, as the osmotic potential influences both bacterial growth and dispersal its potential role in determining the spatial distributions and activity should not be neglected.

\section{Relevance for Field Conditions}

Land degradation by salts is a major threat in arid and semiarid regions of the world, which is mainly caused by low rainfall and high evapotranspiration (Rengasamy, 2006). Furthermore, this problem is anticipated to worsen in future due to irrigation and clearing of the native vegetation especially in agricultural lands (Pannell and Ewing, 2006; Rengasamy, 2006). However, the steadily increasing global population necessitates land use changes toward agriculture, which will at the same time also increase the amount of contaminants (primarily pesticides) applied to the soil. Given the fact that soil is characterized by a high spatial heterogeneity of degrading microorganisms, it is necessary to assess how this heterogeneity in combination with increasing salinization will affect contaminant biodegradation. Indeed, this is a rather complex question as the spatial distribution of degrading organisms in the field is not known a priori and, moreover, difficult to assess and control in replicated, comparative experiments (Dechesne et al., 2014). Therefore, we used microcosm experiments, which allow for defined changes of the relevant conditions but do not incorporate the full complexity of the soil environment. These simplifications, however, constitute a prerequisite to better understand the importance of single aspects in natural systems (Drake et al., 1996). Nonetheless, transferring our findings to natural soil systems, one needs to acknowledge that other factors may also influence the processes elucidated in this study. Especially the matric potential, which is the second major determinant of the water potential in terrestrial habitats, is known to adversely affect bacterial dispersal and substrate diffusion processes in soil (Harris, 1981; Dechesne et al., 2008). This was addressed by several studies without consideration of the osmotic potential. However, future studies should focus on the combined effects of osmotic and matric potential, in particular if considering that decreasing water amounts in soils always result in higher salt concentrations (Chowdhury et al., 2011).

Our work demonstrates that it is important to consider the spatial distribution of degraders as a driving factor for biodegradation. Hence, bacterial dispersal and especially bacterial dispersal along fungal mycelia should be facilitated by avoiding (i) desiccation and high evapotranspiration causing low osmotic potentials, and (ii) the energy-intensive mechanical mixing of soil. The latter prevents the mycelium development of fungi (Lamar et al., 1994), which we demonstrated to counteract the disadvantages of a heterogeneous bacterial distribution. Taking into account a length of up to $10^{4} \mathrm{~m}$ of hyphae per g of soil (Ritz and Young, 2004) and a high tolerance toward low water activities and matric potentials, fungi seem to be a suitable and energy-efficient but yet unexploited alternative to conventional remediation approaches (Harms et al., 2011).

\section{AUTHOR CONTRIBUTIONS}

AW designed the research and performed the laboratory work. AW, SK, TB, FC, and MT analyzed the data. SK, TB, FC, KF, MT, HH, AM, LW, and MK provided consultation for the work. AW wrote the manuscript. All authors contributed significantly to the preparation of the manuscript and approve its submission.

\section{ACKNOWLEDGMENTS}

This work was funded by the Helmholtz Association via the integrated project Controlling Chemicals' Fate of the research topic Chemicals In The Environment (CITE) within the research programme Terrestrial Environment. The authors thank Manuel Trost, Rita Remer, and Jana Reichenbach for skilled experimental help and the reviewers for their helpful comments on the article.

\section{SUPPLEMENTARY MATERIAL}

The Supplementary Material for this article can be found online at: http://journal.frontiersin.org/article/10.3389/fmicb. 2016.01214 


\section{REFERENCES}

Arias-Estévez, M., López-Periago, E., Martínez-Carballo, E., Simal-Gándara, J., Mejuto, J.-C., and García-Río, L. (2008). The mobility and degradation of pesticides in soils and the pollution of groundwater resources. Agric. Ecosyst. Environ. 123, 247-260. doi: 10.1016/j.agee.2007.07.011

Bååth, E., and Arnebrant, K. (1994). Growth rate and response of bacterial communities to $\mathrm{pH}$ in limed and ash treated forest soils. Soil Biol. Biochem. 26, 995-1001. doi: 10.1016/0038-0717(94)90114-7

Badawi, N., Johnsen, A. R., Sørensen, J., and Aamand, J. (2013). Centimeterscale spatial variability in 2-methyl-4-chlorophenoxyacetic acid mineralization increases with depth in agricultural soil. J. Environ. Qual. 42, 683-689. doi: 10. 2134/jeq2012.0397

Banitz, T., Fetzer, I., Johst, K., Wick, L. Y., Harms, H., and Frank, K. (2011a). Assessing biodegradation benefits from dispersal networks. Ecol. Model. 222, 2552-2560. doi: 10.1016/j.ecolmodel.2010.07.005

Banitz, T., Johst, K., Wick, L. Y., Schamfuß, S., Harms, H., and Frank, K. (2013). Highways versus pipelines: contributions of two fungal transport mechanisms to efficient bioremediation. Environ. Microbiol. Rep. 5, 211-218. doi: $10.1111 / 1758-2229.12002$

Banitz, T., Wick, L. Y., Fetzer, I., Frank, K., Harms, H., and Johst, K. (2011b). Dispersal networks for enhancing bacterial degradation in heterogeneous environments. Environ. Pollut. 159, 2781-2788. doi: 10.1016/j.envpol.2011. 05.008

Chang, W. S., van de Mortel, M., Nielsen, L., Nino de Guzman, G., Li, X., and Halverson, L. J. (2007). Alginate production by Pseudomonas putida creates a hydrated microenvironment and contributes to biofilm architecture and stress tolerance under water-limiting conditions. J. Bacteriol. 189, 8290-8299. doi: 10.1128/JB.00727-07

Chen, C.-Y., Nace, G. W., and Irwin, P. L. (2003). A $6 \times 6$ drop plate method for simultaneous colony counting and MPN enumeration of Campylobacter jejuni, Listeria monocytogenes, and Escherichia coli. J. Microbiol. Methods 55, 475-479. doi: 10.1016/S0167-7012(03)00194-5

Cho, J.-C., and Tiedje, J. M. (2000). Biogeography and degree of endemicity of fluorescent pseudomonas strains in soil. Appl. Environ. Microbiol. 66, 5448-5456. doi: 10.1128/AEM.66.12.5448-5456.2000

Chowdhury, N., Marschner, P., and Burns, R. (2011). Response of microbial activity and community structure to decreasing soil osmotic and matric potential. Plant Soil 344, 241-254. doi: 10.1007/s11104-011-0743-9

Cruz, M. S. R., Jones, J. E., and Bending, G. D. (2008). Study of the spatial variation of the biodegradation rate of the herbicide bentazone with soil depth using contrasting incubation methods. Chemosphere 73, 1211-1215. doi: 10.1016/j.chemosphere.2008.07.044

Csonka, L. N. (1989). Physiological and genetic responses of bacteria to osmotic stress. Microbiol. Rev. 53, 121-147.

Czaban, J., Gajda, A., and Wróblewska, B. (2007). The motility of bacteria from rhizosphere and different zones of winter wheat roots. Pol. J. Environ. Stud. 16,301 .

Dechesne, A., Badawi, N., Aamand, J., and Smets, B. F. (2014). Fine scale spatial variability of microbial pesticide degradation in soil: scales, controlling factors, and implications. Front. Microbiol. 5:667. doi: 10.3389/fmicb.2014.00667

Dechesne, A., Or, D., Gülez, G., and Smets, B. F. (2008). The porous surface model, a novel experimental system for online quantitative observation of microbial processes under unsaturated conditions. Appl. Environ. Microbiol. 74, 5195-5200. doi: 10.1128/AEM.00313-08

Dechesne, A., Owsianiak, M., Bazire, A., Grundmann, G. L., Binning, P. J., and Smets, B. F. (2010a). Biodegradation in a partially saturated sand matrix: compounding effects of water content, bacterial spatial distribution, and motility. Environ. Sci. Technol. 44, 2386-2392. doi: 10.1021/es902760y

Dechesne, A., Wang, G., Gulez, G., Or, D., and Smets, B. F. (2010b). Hydrationcontrolled bacterial motility and dispersal on surfaces. Proc. Natl. Acad. Sci. U.S.A 107, 14369-14372. doi: 10.1073/pnas.1008392107

Drake, J. A., Huxel, G. R., and Hewitt, C. L. (1996). Microcosms as models for generating and testing community theory. Ecology 77, 670-677. doi: 10.2307/22 65489

Fulthorpe, R. R., Roesch, L. F. W., Riva, A., and Triplett, E. W. (2008). Distantly sampled soils carry few species in common. ISME J. 2, 901-910. doi: 10.1038/ ismej. 2008.55
Furuno, S., Foss, S., Wild, E., Jones, K. C., Semple, K. T., Harms, H., et al. (2012). Mycelia promote active transport and spatial dispersion of polycyclic aromatic hydrocarbons. Environ. Sci. Technol. 46, 5463-5470. doi: 10.1021/es30 0810b

Gennari, M., Abbate, C., Porta, V. L., Baglieri, A., and Cignetti, A. (2007). Microbial response to Na2SO4 additions in a volcanic soil. Arid Land Res. Manage. 21, 211-227. doi: 10.1080/15324980701428732

Hansen, S. K., Haagensen, J. A., Gjermansen, M., Jorgensen, T. M., Tolker-Nielsen, T., and Molin, S. (2007). Characterization of a Pseudomonas putida rough variant evolved in a mixed-species biofilm with Acinetobacter sp. strain C6. J. Bacteriol. 189, 4932-4943. doi: 10.1128/JB.00041-07

Harms, H., Schlosser, D., and Wick, L. Y. (2011). Untapped potential: exploiting fungi in bioremediation of hazardous chemicals. Nat. Rev. Microbiol. 9, 177-192. doi: 10.1038/nrmicro2519

Harms, H., and Wick, L. Y. (2006). Dispersing pollutant-degrading bacteria in contaminated soil without touching it. Eng. Life Sci. 6, 252-260. doi: 10.1002/elsc.200620122

Harris, R. (1981). "Effect of water potential on microbial growth and activity," in Water Potential Relations in Soil Microbiology, eds J. F. Parr, W. R. Gardner, and L. F. Elliott (Madison, WI: Soil Science Society of America Special Publication No. 9), 23-95.

Hol, F. J., Hubert, B., Dekker, C., and Keymer, J. E. (2016). Density-dependent adaptive resistance allows swimming bacteria to colonize an antibiotic gradient. ISME J. 10, 30-38. doi: 10.1038/ismej.2015.107

Holden, P. A., and Firestone, M. K. (1997). Soil microorganisms in soil cleanup: how can we improve our understanding? J. Environ. Qual. 26, 32-40. doi: 10.2134/jeq1997.00472425002600010006x

Holden, P. A., Halverson, L. J., and Firestone, M. K. (1997). Water stress effects on toluene biodegradation by Pseudomonas putida. Biodegradation 8, 143-151. doi: 10.1023/A:1008237819089

Hussain, S., Devers-Lamrani, M., Spor, A., Rouard, N., Porcherot, M., Beguet, J., et al. (2013). Mapping field spatial distribution patterns of isoproturonmineralizing activity over a three-year winter wheat/rape seed/barley rotation. Chemosphere 90, 2499-2511. doi: 10.1016/j.chemosphere.2012.1 0.080

Johnsen, A. R., Bendixen, K., and Karlson, U. (2002). Detection of microbial growth on polycyclic aromatic hydrocarbons in microtiter plates by using the respiration indicator WST-1. Appl. Environ. Microbiol. 68, 2683-2689. doi: 10.1128/AEM.68.6.2683-2689.2002

Kahm, M., Hasenbrink, G., Lichtenberg-Fraté, H., Ludwig, J., and Kschischo, M. (2010). Grofit: fitting biological growth curves with R. J. Stat. Softw. 33, 1-21. doi: $10.18637 /$ jss.v033.i07

Kohlmeier, S., Smits, T. H., Ford, R. M., Keel, C., Harms, H., and Wick, L. Y. (2005). Taking the fungal highway: mobilization of pollutant-degrading bacteria by fungi. Environ. Sci. Technol. 39, 4640-4646. doi: 10.1021/es047979z

Kristoffersen, S. M., Ravnum, S., Tourasse, N. J., Økstad, O. A., Kolstø, A.-B., and Davies, W. (2007). Low concentrations of bile salts induce stress responses and reduce motility in Bacillus cereus ATCC 14570. J. Bacteriol. 189, 5302-5313. doi: 10.1128/JB.00239-07

Lamar, R. T., Davis, M. W., Dietrich, D. M., and Glaser, J. A. (1994). Treatment of a pentachlorophenol-and creosote-contaminated soil using the lignin-degrading fungus Phanerochaete sordid a: a field demonstration. Soil Biol. Biochem. 26, 1603-1611. doi: 10.1016/0038-0717(94)90312-3

Martinez-Beltran, J., and Manzur, C. L. (2005). "Overview of salinity problems in the world and FAO strategies to address the problem," in Proceedings of the International Salinity Forum, Riverside (Riverside, CA: USDA-ARS Salinity Lab), 311-313.

Martinez-Garcia, E., Nikel, P. I., Chavarria, M., and De Lorenzo, V. (2014). The metabolic cost of flagellar motion in Pseudomonas putida KT2440. Environ. Microbiol. 16, 291-303. doi: 10.1111/1462-2920.12309

Matilla, M. A., Ramos, J. L., Duque, E., De Dios Alché, J., Espinosa-Urgel, M., and Ramos-González, M. I. (2007). Temperature and pyoverdine-mediated iron acquisition control surface motility of Pseudomonas putida. Environ. Microbiol. 9, 1842-1850. doi: 10.1111/j.1462-2920.2007.01286.x

Monard, C., McHergui, C., Nunan, N., Martin-Laurent, F., and Vieublé-Gonod, L. (2012). Impact of soil matric potential on the fine-scale spatial distribution and activity of specific microbial degrader communities. FEMS Microbiol. Ecol. 81, 673-683. doi: 10.1111/j.1574-6941.2012.01398.x 
Norbeck, J., and Blomberg, A. (1998). Amino acid uptake is strongly affected during exponential growth of Saccharomyces cerevisiae in $0.7 \mathrm{M} \mathrm{NaCl}$ medium. FEMS Microbiol. Lett. 158, 121-126. doi: 10.1111/j.1574-6968.1998.tb12810.x

Oren, A. (1999). Bioenergetic aspects of halophilism. Microbiol. Mol. Biol. Rev. 63, 334-348.

Oren, A. (2001). The bioenergetic basis for the decrease in metabolic diversity at increasing salt concentrations: implications for the functioning of salt lake ecosystems. Hydrobiologia 466, 61-72. doi: 10.1023/A:1014557116838

Pallud, C., Dechesne, A., Gaudet, J. P., Debouzie, D., and Grundmann, G. L. (2004). Modification of spatial distribution of 2,4-dichlorophenoxyacetic acid degrader microhabitats during growth in soil columns. Appl. Environ. Microbiol. 70, 2709-2716. doi: 10.1128/AEM.70.5.2709-2716.2004

Pannell, D. J., and Ewing, M. A. (2006). Managing secondary dryland salinity: options and challenges. Agric. Water Manage. 80, 41-56. doi: 10.1016/j.agwat.2005.07.003

Pinheiro, M., Garnier, P., Beguet, J., Martin Laurent, F., and Vieublé Gonod, L. (2015). The millimetre-scale distribution of 2,4-D and its degraders drives the fate of 2,4-D at the soil core scale. Soil Biol. Biochem. 88, 90-100. doi: 10.1016/j.soilbio.2015.05.008

Pion, M., Bshary, R., Bindschedler, S., Filippidou, S., Wick, L. Y., Job, D., et al. (2013a). Gains of bacterial flagellar motility in a fungal world. Appl. Environ. Microbiol. 79, 6862-6867. doi: 10.1128/AEM.01393-13

Pion, M., Spangenberg, J. E., Simon, A., Bindschedler, S., Flury, C., Chatelain, A., et al. (2013b). Bacterial farming by the fungus. Proc. Biol. Sci. 280:20132242. doi: $10.1098 / \mathrm{rspb} .2013 .2242$

Rashid, M. H., and Kornberg, A. (2000). Inorganic polyphosphate is needed for swimming, swarming, and twitching motilities of Pseudomonas aeruginosa. Proc. Natl. Acad. Sci. U.S.A. 97, 4885-4890. doi: 10.1073/pnas.060030097

R Core Team (2014). R: A Language And Environment For Statistical Computing. Vienna: R Foundation for Statistical Computing.

Rengasamy, P. (2006). World salinization with emphasis on Australia. J. Exp. Bot. 57, 1017-1023. doi: 10.1093/jxb/erj108

Ritz, K., and Young, I. M. (2004). Interactions between soil structure and fungi. Mycologist 18, 52-59. doi: 10.1017/S0269915X04002010

Rodriguez-Cruz, M. S., Jones, J. E., and Bending, G. D. (2006). Field-scale study of the variability in pesticide biodegradation with soil depth and its relationship with soil characteristics. Soil Biol. Biochem. 38, 2910-2918. doi: 10.1016/j.soilbio.2006.04.051

Schamfuß, S., Neu, T. R., van der Meer, J. R., Tecon, R., Harms, H., and Wick, L. Y. (2013). Impact of mycelia on the accessibility of fluorene to PAH-degrading bacteria. Environ. Sci. Technol. 47, 6908-6915. doi: 10.1021/es304378d

Semple, K. T., Doick, K. J., Wick, L. Y., and Harms, H. (2007). Microbial interactions with organic contaminants in soil: definitions, processes and measurement. Environ. Pollut. 150, 166-176. doi: 10.1016/j.envpol.2007.07.023

Soulas, G., and Lagacherie, B. (2001). Modelling of microbial degradation of pesticides in soils. Biol. Fertil. Soils 33, 551-557. doi: 10.1007/s0037401 00363
Soutourina, O. A., Semenova, E. A., Parfenova, V. V., Danchin, A., and Bertin, P. (2001). Control of bacterial motility by environmental factors in polarly flagellated and peritrichous bacteria isolated from lake baikal. Appl. Environ. Microbiol. 67, 3852-3859. doi: 10.1128/AEM.67.9.3852-3859.2001

Stark, J. M., and Firestone, M. K. (1995). Mechanisms for soil moisture effects on activity of nitrifying bacteria. Appl. Environ. Microbiol. 61, 218-221.

Tripathi, S., Kumari, S., Chakraborty, A., Gupta, A., Chakrabarti, K., and Bandyapadhyay, B. K. (2006). Microbial biomass and its activities in saltaffected coastal soils. Biol. Fertil. Soils 42, 273-277. doi: 10.1007/s00374-0050037-6

Vieublé Gonod, L., Chadoeuf, J., and Chenu, C. (2006). Spatial distribution of microbial 2,4-dichlorophenoxy acetic acid mineralization from field to microhabitat scales. Soil Sci. Soc. Am. J. 70, 64. doi: 10.2136/sssaj2004.0034

Vinther, F. P., Brinch, U., Elsgaard, L., Fredslund, L., Iversen, B. V., Torp, S., et al. (2008). Field-scale variation in microbial activity and soil properties in relation to mineralization and sorption of pesticides in a sandy soil. J. Environ. Qual.37, 1710-1718. doi: 10.2134/jeq2006.0201

Wai, S. N., Mizunoe, Y., Takade, A., Kawabata, S.-I., and Yoshida, S.-I. (1998). Vibrio cholerae O1 strain TSI-4 produces the exopolysaccharide materials that determine colony morphology, stress resistance, and biofilm formation. Appl. Environ. Microbiol. 64, 3648-3655.

Warikoo, V., McInerney, M. J., Robinson, J. A., and Suflita, J. M. (1996) Interspecies acetate transfer influences the extent of anaerobic benzoate degradation by syntrophic consortia. Appl. Environ. Microbiol. 62, 26-32.

Wei, Y., Wang, X., Liu, J., Nememan, I., Singh, A. H., Weiss, H., et al. (2011). The population dynamics of bacteria in physically structured habitats and the adaptive virtue of random motility. Proc. Natl. Acad. Sci. U.S.A. 108, 4047-4052. doi: 10.1073/pnas.1013499108

Wick, L. Y., Remer, R., Würz, B., Reichenbach, J., Braun, S., Schäfer, F., et al (2007). Effect of fungal hyphae on the access of bacteria to phenanthrene in soil. Environ. Sci. Technol. 41, 500-505. doi: 10.1021/es061407s

Worrich, A., König, S., Miltner, A., Banitz, T., Centler, F., Frank, K., et al. (2016). Mycelia-like networks increase bacterial dispersal, growth and biodegradation in a model ecosystem at varying water potentials. Appl. Environ. Microbiol. 82, 2902-2908. doi: 10.1128/AEM.03901-15

Conflict of Interest Statement: The authors declare that the research was conducted in the absence of any commercial or financial relationships that could be construed as a potential conflict of interest.

Copyright (C) 2016 Worrich, König, Banitz, Centler, Frank, Thullner, Harms, Miltner, Wick and Kästner. This is an open-access article distributed under the terms of the Creative Commons Attribution License (CC BY). The use, distribution or reproduction in other forums is permitted, provided the original author (s) or licensor are credited and that the original publication in this journal is cited, in accordance with accepted academic practice. No use, distribution or reproduction is permitted which does not comply with these terms. 